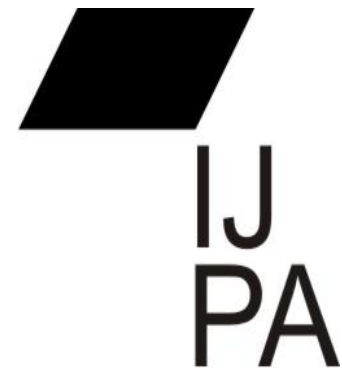

ISSN $2460-0369$

\title{
EFEKTIVITAS PELAYANAN PUBLIK ONLINE PADA BADAN PENDAPATAN DAN ASET DAERAH PROVINSI NUSA TENGGARA TIMUR DI KABUPATEN TIMOR TENGAH SELATAN
}

\author{
FELIX VENANCIO SIKONE \\ WILIAM DJANI \\ ZET SONI LIBING \\ Universitas Nusa Cendana Kupang \\ felixsikone@yahoo.com
}

\begin{abstract}
The results of the study show that online services at the Samsat office of the Regional Financial and Asset Management Revenue Board of East Nusa Tenggara Province have been effective because they have given satisfaction through simple, easy, smooth, convoluted mechanisms, procedures and service quality., clear, definite and service can provide security, comfort, and economics as well as timeliness, however there are still obstacles that need to be addressed, namely network disruption, frequent power outages, only one vendor tool, limited service hours to at 2:00 p.m., the registration window and the delivery counter are only one and have not been too socialized about the requirements for paying taxes to the public. Therefore it is necessary to reform the obstacles above by preparing backup vendor tools, increasing service hours for the taxpayers, adding registration and delivery counters as well as socializing the requirements for paying taxes to the public.
\end{abstract}

Keywords: Effectiveness of Public Services, E-Govenment, E-Services, Samsat Online 
Abstrak:: Hasil penelitian menunjukan bahwa pelayanan online pada kantor Samsat Badan Pendapatan Pengelola Keuangan dan Aset Daerah Provinsi Nusa Tenggara Timur di Kabupaten Timor Tengah Selatan telah efektif karena telah memberikan kepuasan melalui mekanisme, prosedur, dan mutu pelayanan yang sederhana, mudah, lancar, tidak berbelit-belit, jelas, pasti dan pelayanan dapat memberikan keamanan, kenyamanan, dan ekonomis serta ketepatan waktu, namun demikian masih terdapat hambatan-hambatan yang perlu dibenahi yaitu sering terganggunya jaringan, sering terjadinya pemadaman listrik, alat vendor yang digunakan hanya satu, jam pelayanan yang terbatas sampai jam 14.00 wita, loket pendaftaran dan loket penyerahan hanya satu dan belum terlalu sosialisasi tentang persyaratan pembayaran pajak kepada masyarakat. Oleh karena itu perlu adanya pembenahan terhadap hambatan-hambatan tersebut diatas dengan menyiapkan alat vendor cadangan, menambah jam pelayanan kepada masyarakat wajib pajak, menambah loket pendaftaran dan penyerahan serta melakukan sosialisasi tentang persyaratan pembayaran pajak kepada masyarakat.

Kata kunci: Efektivitas Pelayanan Publik, E-Govenment, EServices, Samsat Online.

\section{PENDAHULUAN}

Penerapan pemerintahan elektronik ditetapkan dalam pasal 349 (ayat 3) Undang-undang Nomor 23 Tahun 2014 tentang pemerintahan Daerah yang mengamanatkan bahwa "Pemerintahan Daerah dapat memanfaatkan teknologi informasi dan komunikasi dalam penyelenggaraan pelayanan publik". Jauh sebelumnya, pemerintahan elektronik telah di atur dalam instruksi presiden Nomor 6 Tahun 2001 tentang telematika untuk mendukung Good Governance. Pelayanan publik berbasis elektronik mempunyai keunggulan yaitu selain murah, mudah dan cepat, juga menutup ruang bagi terjadinya KKN. Bisa lebih luas menjangkau masyarakat dan dapat mengakses melalui internet tanpa harus 
datang ke kantor pemerintah sehingga hambatan geografis dan struktural dapat di atasi oleh sistem.

Menurut As Moener (1995:73), Ada tiga model pemerintahan elektronik, yaitu government to citizen atau government to customer (G2C). Kedua, government to business (G2B). Dan government to government (G2G). Model G2C dalam bentuk penyampaian layanan publik dan informasi kepada masyarakat seperti pelayanan pajak on-line telah dilaksanankan di berbagai daerah maju, Eropa dan AS, dan untuk pelayanan pajak kendaraan bermotor telah diterapkan pada berbagai daerah dalam rangka implementasi Reformasi Birokrasi pada pemerintahan daerah, termasuk di Provinsi Nusa Tenggara Timur, Unit Pelaksa Terpadu SAMSAT Online Timor Tengah Selatan.

Sistem pelayanan elektronik pada SAMSAT dilakukan berdasarkan memorandum of Understanding (MOU) sebagai bentuk kerja sama yang di tuangkan dalam keputusan Kepala Badan Pendapatan Pengelola Keuangan Dan Aset Daerah (BPPKAD) Nomor PERDA.II.3/000.037/1502/2009 dan Nomor 49/BNTT/XII/09 tentang sistem Administrasi Manunggal Satu Atap (SAMSAT) Online.

Tujuan dari kantor SAMSAT Online adalah meningkatkan pelayanan kepada masyarakat dengan memberikan pelayanan melakukan kewajiban mengurus STNK, membayar pajak maupun sumbangan wajib dana kecelakaan lalu lintas jalan (SWDKLLJ) lebih mudah tepat waktu dan terkendali serta pada akhirnya dapat meningkatkan pendapatan asli daerah (PAD). Sistem ini juga mempermudah sistem pendataan dan pembayaran pajak kendaraan bermotor atau wajib pajak di SAMSAT Timor Tengah Selatan secara lebih akurat dan pasti.

Terlepas dari segala keunggulan pelayanan berbasis teknologi informasi setelah penerapannya dirasakan sistem ini belum memberikan hasil yang maksimal, oleh karena pihak lain sistem pelayanan elektronik sangat tergantung pada dukungan jaringan dan pasokan listrik yang harus stabil. Oleh sebab itu jaringan adalah salah satu penyebab terhambatnya pelayanan online begitu juga 
dengan pemadaman listrik oleh PLN yang sering terjadi telah membawah persoalan sendiri, baik karena macetnya pelayanan maupun berdampak pada gangguan pada sistem hardware serta software yang memang sangat sensitif. Demikian pula aspek budaya serta perilaku pelayanan dan perilaku masyarakat dalam menyikapi pelayanan online yang memang memerlukan penyesuaian dalam persyaratan keterampilan teknis dalam pengelolaan maupun akses terhadap informasi pelayanan.

Berdasarka ketiga masalah tersebut dukungan jaringan, pasokan listrik yang harus stabil dan pengetahuan masyarakat terhadap Pelayanann Samsat Online.

1. Dukungan Jaringan, berdasarkan wawancaran dengan beberapa pegawai di Kantor Samsat pada tanggal 18 juli 2018, bernama Marianus mengatakan bahwa jaringan sering atau biasa terputus ini yang menyebabkan pelayanan yang bersifat Online sering terhambat dilaksanan.

2. Pasokan Listrik, kemudian berdasarkan pembicaraan yang saya lakukan dengan pegawai Kantor Samsat Badan Pendapatan Pengelola Keuangan dan Aset Daerah mengatakan bahwa listrik sering padam biasanya 1 minggu sekali ini juga yang meyebabkan terhambat memberikan pelayanan kepada masyarakat.

\section{TINJAUAN PUSTAKA}

\subsection{Konsep Efektivitas}

\subsection{Konsep Pelayanan Publik}

\subsection{Pergeseran Paradigma}

\subsection{Konsep E-Government dan Pelayanan Berbasis Online}

\section{KERANGKA PEMIKIRAN}


Model kerangka pemikiran yang berkaitan dengan Efektivitas Pelayanan Publik secara Online di Kantor Bersama SAMSAT Badan Pendapatan dan Aset Daerah wilayah Timor Tengah Selatan.

Dapat di deskripsikan dari Input, Output dan Proses dalam studi efektivitas Pelayanan Publik akan di ketahui hasilnya atau Output jika Input dan Proses Pelayanan dapat berjalan secara efektif.

Suatu pelayanan publik akan menjadi efektif dapat ketahui dari beberapa indikator (a). Mekanisme yang berkaitan dengan alur atau tahapan dalam pembayaran pajak atau bagian-bagian mana sajakah yang harus di lewati oleh wajib pajak dalam pendaftaran Online, (b). prosedur pelayanan berkaitan dengan persyaratan apa saja yang harus disiapkan oleh wajib pajak dalam membayar pajak, (c).waktu penyelesaian berkaitan dengan ketepatan dan sesuai standar pelayanan yang di tetapkan kantor bersama SAMSAT, (d). Mutu pelayana berkaitan dengan kepuasan yang diterima wajib pajak berupa produk kualitas barang.

Dengan demikian ke 4 indikatot tersebut akan dijadikan studi pelayanan publik yang berkaitan dengan efektivitas pelayanan antara pelayanan secara manual dan Online di Kantor bersama SAMSAT Badan Pendapatan Pengelola Keuangan dan Aset Daerah (BPPKAD) Wilayah Timor Tengah Selatan.

\section{METODE PENELITIAN}

\section{Jenis Penelitian}

Jenis penelitian yang digunakan adalah penelitian deskriptif dengan metode pendekatan kualitatif, sehubungan dengan hal tersebut, Wiliams (1993:19), mengatakan bahwa salah satu kareteristik dari penelitian kualitatif adalah sangat kaya dan sarat dengan deskripsi, penelitian terdorong untuk memahami fenomena secara menyeluruh sesuai konteks dan melakukan analisis yang holistik yang di kemukakan secara deskriptif dalam kesimpulan kesimpulan. 


\section{PEMBAHASAN}

\section{Efektivitas Pelayanan Online pada Samsat Badan Pendapatan Pengelola} Keungan Dan Aset Daerah Kabupaten Timor Tengah Selatan.

Mekanisme merupakan suatu rangkaian kerja sebuah alat yang digunakan dalam menyelesaikan sebuah masalah yang berkaitan dengan proses kerja, tujuannya adalah untuk menyelesaikan hasil yang maksimal serta mengurangi kegagalan. ( moenar, 2001:21 ). Selanjutnya dikemukakan oleh ( Bagus, 1996:10 ) Mekanisme adalah interaksi bagian satu dengan bagian lainnya dalam suatu sistem secara keseluruhan untuk menghasilkan fungsi atau kegiatan sesuai dengan tujuan.

Kantor Samsat Online Badan Pendapatan Pengelola Keuangan Dan Aset Daerah Kabupaten Timor Tengah Selatan, dalam pelayanan berupaya untuk melayani masyarakat yang datang melakukan pengurusan pembayaran pajak karena pada dasarnya penggunaan teknologi perangkat yang ditetapkan di kantor Samsat Badan Pendapatan Pengelola Keungan dan Aset Daerah adalah berbasis Online yang meliputi:

1. Penggunaan Software atau perangkat lunak yaitu program aplikasi yang di tulis untuk memprogram tertentu untuk ditetapkan pada PKB dan STNK, perangkat Online yang digunakan ada dua yaitu Server ( komputer ). Sistem ini terprogram terdiri atas kendaraan lama atau baru, jenis, waktu, kapan pembayaran pajak serta identitas pemilik kendaraan, data ini sangat di perlukan untuk keamanan.

2. Perangkat keras Hardware adalah sebuah komponen fisik yang digunakan samsat untuk menjalankan perintah yang di programkan :

a. Alat vendor ( $\mathrm{CPU}$ ) yang digunakan hanya satu adalah sebagai pengendali pada komputer yang mengatur semua instruksi program dan semua aktivitas yang dilakukan dalam komputer, ini disebut otak komputer, yang terhubung ke server Pusat.

b. Komputer untuk menyimpan data pajak, STNK dan Entry data. 
c. Microphone yang di gunakan samsat adalah perangkat keras suara untuk memanggil wajib pajak

d. Rauter adalah perangkat keras yang berfungsi untuk menghubungkan beberapa jaringan komputer yang memiliki jaringan akses yang sama.

e. Printer yang digunakan untuk mencetak STNK dan bukti pajak.

\section{Prosedur Pelayanan, Yang Berkaitan Dengan Tahap Pelayanan Kantor Samsat}

Menurut Ratminato dan Winarsi ( 2005:209 ), prosedur pelayanan adalah rangkaian proses atau tata cara kerja yang berkaitan satu sama lain, sehingga menunjukan adanya tahapan secara jelas dan pasti serta cara-cara yang harus ditempuh dalam rangkaian penyelesaian suatu pelayanan. Selanjutnya di kemukakan (Ida Nuraida,2008:35)Prosedur adalah langkah-langkah ( atau pelaksanaan-pelaksanaan pekerjaan ), dimana pekerjaan tersebut dilakukan, berhubungan dengan apa yang dilakukan, sebagaimana melakukannya, dan siapa yang melakukannya.

Berdasarkan pengertian prosedur pelayanan tersebut di atas maka dapat dijelaskan bahwa empat tata cara yang dimaksut sebagai berikut:

a. Tata cara pengajuan permohonan ialah tahapan-tahapan yang jelas dan pasti serta cara-cara yang harus dilaksanakan dalam rangkaian pengajuan suatu permohonan pelayanan agar permohonan yang ajukan tersebut dapat dilayanani atau di proses ketahap berikutnya. Pada tahap ini biasanya memuat tahap-tahap dan cara-cara yang harus dilaksanakan dan dipenuhi oleh seseorang pemohon yang mengajukan permohonan pelayanan tertentu kepada petugas atau pejabat yang berwenang memberikan pelayanan tersebut.

b. Tata cara penanganan pelayanan, ialah tahapan-tahapan yang jelas dan pasti serta cara-cara yang harus dilaksanankan dalam rangka menindak lanjuti atau menangani suatu permohonan pelayanan yang di ajukan, pada tahap ini petugas atau pejabat yang berwenang harus menangani dan memproses 
permohonan pelayanan yang diajukan sesuai dengan tata cara kerja dan ketentuan yang berlaku.

c. Tata cara penyampaian hasil pelayanan, ialah tahapan-tahapan yang jelas dan pasti serta cara-cara yang harus ditempuh dalam rangka menyampaikan hasil pelayanan yang telah selesai ditangani. Pada tahap ini permohonan pelayanan yang telah ditangani oleh petugas atau pejabat yang berwenang akan disampaikan hasilnya kepada pemohon yang bersangkutan. Pemohon dapat menerima hasil pelayanan dengan memenuhi ketentuan-tertentu yang berlaku dan terkait dengan jenis pelayanan yang diajukan.

d. Tata cara penyampaian pengaduan pelayanan, adalah tahapan-tahapan yang jelas dan pasti serta cara-cara yang harus ditempuh untuk dapat menyampaikan pengaduan yang berhubungan dengan masalah pelayanan, pemohon dapat mengadukan atau mengajukan masalah ketidak puasan dan masalah-masalah lain yang berhubungan dengan proses pelayanan pada setiap tahapnya.

\section{Mutu Pelayanan.}

Bahwa sebelum menggunakan aplikasi Samsat Online secara penuh. Terlebih dahulu melakukan log-in, kemudian memasukan nama pemakaian dan kata sandi yang digunakan setelah itu meng-klik pilihan OK.

Dalam menu master tabel terdapat beberapa sub-Menu yaitu Master Kendaraan, DPPKB dan BBN, jenis pungutan, jenis permohonan, jenis kendaraan, kode pos, administrasi, SWDKLLJ, bahan bakar, penggunaan, merek kendaraan, kepemilikan, lokasi dan hari libur nasional.

Adapun penjelasan berkaitan dengan beberapa sub-menu dari tampilan Master Tabel sebagai berikut :

1. Master ( Data ) kendaraan dirancang untuk memasukan nomor kendaraan beserta dengan uraian kendaraannya sebagaimana terdapat dalam Kepmendagri No.29 Tahun 2002 yang pada intinya mengatur tentang Nomor Kendaraan yang bersifat standar. Dalam pilihan Master ( Data ) Kendaraan masih terbagi lagi menjadi 2 ( Dua ) bagian yaitu dipergunakan untuk pengolahan data ( entry data) dan untuk menampilkan data secara 
keseluruhan ( listing data ). Pada entry data operator data operator dapat pengolah data mulai dari memasukan data baru, merubah data yang sudah dimasukan bahkan dapat menghapusnya dengan menggunakan tanda yang tersedia pada monitor. Navigasi toolbar tersebut dapat digunakan pada setiap menu aplikasi dengan fungsi yang sama dan dapat diaktifkan dengan cara melakukan klik kanan di mouse pada navigasi toolbar ataupun dengan menggunakan keyboard pada tuts-tuts tertentu yang tersedia. Sedangkan untuk Master ( info pembayaran ) kendaraan maka nomor polisi diisi sesuai dengan nomor kendaraan yang dicari dan setelah memasukan nomor polisi maka pilihan tombol proses untuk pencarian data kendaraan, dan setelah proses pencarian selesai maka akan ditampilkan data kendaraan.

2. Pada sub-menu DPPKB dan BBN juga tersedia navigasi toolbar, dipergunakan untuk mengolah data ( entry data ) dan untuk menampilkan data ( listing data ). Entry data, jenis kendaraan, merk, tipe, bahan bakar, gol. SWDKLLJ biasa dan gol. SWDKLLJ umum dapat tampil secara otomatis dengan meng-klik pada panah kebawah yang berada pada masing-masing isinya dan setelah itu keterangan dan isi silinder dimasukan secara manual dan pada listing data dipergunakan untuk menampilkan data yang sudah dimasukan.

3. Pada sub-menu jenis pungutan terdiri dari navigasi toolbar, entry data yang dipergunakan untuk mengolah data dan listing data yang dipergunakan untuk menampilkan data keseluruhan. Pada bagian ini berisikan kode pungutan, jenis pungutan, sub/header, kode header, ayat, jenis biaya, pilihan, dan target intern. Jenis pungutan harus dimasukan seluruhnya dan pada saat mengisi harus teliti dan berhati-hati oleh karena berpengaruh pada menu yang lainnya dan setelah melakukan input kode rekening maka menggunakan navigasi toolbar simpan atau data baru bila ingin membuat data baru atau keluar bila sudah selesai menginput jenis pungutan.

4. Sub-Menu permohonan terdiri dari navigasi toolbar, entry, data yang dipergunakan untuk mengolah data dan listing data yang dipergunakan untuk menampilkan data keseluruhan. Untuk melihat tampilan keseluruhan dari jenis permohonan maka dapat melakukan klik pada kolom listing data maka 
akan muncul tampilan isian keterangan untuk diisi sesuai dengan permohonan.

5. Sub-Menu jenis kendaraan juga terdiri dari navigasi toolbar, entry data yang digunakan untuk mengolah data dan listing data yang dipergunakan untuk menampilkan data keseluruhan, yang ada dalam tampilan monitor meliputi kode jenis, jenis kendaraan, sub/header, kode header dan tipe kendaraan.

6. Sub-Menu Kode pos terdiri dari navigasi toolbar, entry data yang dipergunakan untuk mengolah data dan listing data yang dipergunakan untuk menampilkan data keseluruhan, yang ada dalam tampilan monitor meliputi Kode Pos, keseluruhan, dan kode lokasi.

7. Sub-Menu Administrasi terdiri dari entry data yang dipergunakan untuk mengolah data dan listing data yang dipergunakan untuk menampilkan data keseluruhan dalam tampilan monitor meliputi biaya administrasi STNK dan BPKB, biaya Administrasi STCK, biaya plat nomor kendaraan roda dua dan roda empat.

8. Sub-Menu SWDKLLJ terdiri dari navigasi toolbar, entry data yang dipergunakan untuk mengolah data dan listing data yang dipergunakan untuk menampilkan data keseluruhan yang ada dalam tampilan monitor yaitu golongan, keterangan, kolom SWDKLLJ baru dan SWDKLLJ lama yang terdiri dari pokok, leges, bulan 1 sd/ 11 yang isi sesuai dengan ketentuan yang berlaku.

9. Sub-Menu Bahab Bakar yang terdiri dari navigasi toolbar, entry data yang dipergunakan untuk mengolah data dan listing data yang dipergunakan untuk menampilkan data keseluruhan yang ada dalam tampilan monitor yaitu kode BBM dan keterangan.

10. Sub-Menu Penggunaan terdiri dari navigasi toolbar, entry data yang dipergunakan untuk mengolah data dan listing data yang dipergunakan untuk menampilkan data keseluruhan yang ada dalam tampilan monitor yaitu kode merk dan keterangan.

11. Sub-Menu Merk kendaraan terdiri dari navigasi toolbar, entry data yang dipergunakan untuk mengolah data dan listing data yang dipergunakan untuk 
menampilkan data keseluruhan yang ada dalam tampilan monitor yaitu kode merk dan keterangan.

12. Sub-Menu Kepemilikan terdiri dari navigasi toolbar, entry data yang dipergunakan untuk mengolah data dan listing data yang dipergunakan untuk menampilkan data keseluruhan yang ada dalam tampilan monitor yaitu kode kepemilikan dan keterangan.

13. Sub-Menu Lokasi yang terdiri dari navigasi toolbar, entry data yang dipergunakan untuk mengolah data dan listing data yang dipergunakan untuk menampilkan data keseluruhan yang ada dalam tampilan monitor yaitu kode lokasi, keterangan, tingkat dan kabupaten.

14. Sub-Menu Hari Libur Nasional terdiri dari navigasi toolbar, entry data yang dipergunakan untuk mengolah data dan listing data yang dipergunakan untuk menampilkan data keseluruhan yang ada dalam tampilan monitor yaitu tanggal dan keterangan.

\section{Hambatan apa saja yang ditemukan dalam pelayanan sistem Online, Faktor Internal dan Faktor Eksternal.}

Pelaksanaan yang dilakukan di Kantor Samsat Timor Tegah Selatan masi terdapat beberapa hambatan yaitu hambatan dilihat dari sisi penyediaan atau petugas yang ada si Samsat Timor Tengah Selatan dan dan hambatan dari masyarakat itu sendiri.

Adapun hambatan-hambatan dari penyediaan atau petugas di Samsat TTS meliputi:

1. Jaringan terganggu, sering terjadi pemadaman listrik, spaning listrik turun sehingga data tidak direkam, solusinya adalah mencocokan dengan pihak Bank secara manual.

2. Alat Vendor digunakan hanya Satu seharusnya disiapkan cadangan dua atau lebih dan mengantisipasi server eror bisa diganti dengan cadangan.

3. Adanya trouble jaringan Online permasalahan yang sering timbul adalah adanya gangguan jaringan. Saat jaringan tidak connect untuk akses internet, maka sistem Online tidak dapat dijalankan. Gangguan Jaringa ini bisa terjadi 
dikarenakan beberapa faktor, baik dari server maupun faktor alam seperti cuaca. Saat adanya gangguan jaringan seperti ini, kegiatan pelayanan terpaksa dihentikan.

4. Jumlah loket yang tersedia pada umumnya hanya dua loket yang tentunya tidak bisa mengatasi banyaknya jumlah wajib pajak sehingga menimbulkan banyaknya antrian.

5. Terbatas pada jam operasiaonal tertentu. Pelayanan pembayaran pajak melalui Online pada umumnya memiliki jam operasional yang lebih singkat sampai jam 14.00 siang.

Sedangkan hambatan-hambatan dari masyarat wajib pajak itu sendiri meliputi :

1. Kartu Tanda Penduduk ( KTP ) asli yang habis masa berlakunya adapun cara menanggulanginya adalah petugas menyarankan agar wajib pajak yang membayar pajak kendaraan.

2. Seringkali wajib pajak lupa tadak membawa persyaratan yang lengkap sehingga petugas samsat meminta agar wajib pajak harus melengkapi kekurangan persyaratan tersebut.

3. Bahwa seringkali wajib pajak tidak membawa kendaraan ketika ingin membayar STNK 5 tahun, padahal diharuskan wajib pajak membawa kendaraan roda dua atau empat untuk di gesek nomor rangkanya.

Pemerintah diharapkan dapat memberikan pelayanan yang efektif dengan memperbaiki kualitas pelayanan melalui hambatan-hambatan yang ada, agar masyarakat merasa puas sehingga berdampak pada kepatutan dan kesadaran wajib pajak serta meningkatnya Pendapatan Asli Daerah ( PAD ).

\section{KESIMPULAN}

Berdasarkan hasil penelitian yang dilaksanakan di Kantor Bersama SAMSAT Badan Pendapatan Pengelola Keuangan dan Aset Daerah Kabupaten Timor Tengah Selatan, maka dapat ditarik kesimpulan sebagai berikut :

1. Pelaksanaan pelayanan berbasis Online di Kantor Samsat Kabupaten Timor Tengah Selatan sudah sesuai dengan standar pelayanan publik yang ditetapkan sehingga memberi kemudahan kepada masyarakat untuk 
melakukan pembayaran pajak kendaraan bermotor dengan waktu yang singkat dan biaya pengurusan administrasi pembayaran pajak kendaraan bermotor yang lebih ringan.

2. Pelaksanaan pelayanan sistem Online di Kantor Samsat Kabupaten Timor Tengah Selatan, sudah sesuia dengan mekanisme dan prosedur yang ada sehingga dalam proses pelayanan kepada masyarat tidak ada tumpang tindih dan pemberian pelayan kepada masyarakat tidak berbelit-belit sehinggga waktu, tenaga dan biaya diatur secara efesien mungkin.

3. Pelayanan sistem Online di Kantor Samsat Kabupaten Timor Tengah Selatan telah memberi kepuasan terhadap masyarakat karena pelayanan sistem Online sangat membantu Masyarakat dari segi waktu, tenaga dan biaya. Selain itu etika pelayanan sistem Online yang dijunjung tinggi di Kantor Samsat Kabupaten Timor Tengah Selatan juga memberi kepuasan terhadap Masyarakat wajib pajak.

4. Hambatan-hambatan dalam pelaksanaan Pelayanan berbasis Online di Kantor Samsat Kabupaten Timor Tengah Selatan meliputi :

1. Jaringan terganggu, sering terjadi pemadaman listrik, spaning listrik turun sehingga data tidak direkam, solusinya adalah mencocokan dengan pihak Bank secara manual.

2. Alat Vendor digunakan hanya Satu seharusnya disiapkan cadangan dua atau lebih dan mengantisipasi server eror bisa diganti dengan cadangan.

3. Adanya trouble jaringan Online permasalahan yang sering timbul adalah adanya gangguan jaringan. Saat jaringan tidak connect untuk akses internet, maka sistem Online tidak dapat dijalankan. Gangguan Jaringa ini bisa terjadi dikarenakan beberapa faktor, baik dari server maupun faktor alam seperti cuaca. Saat adanya gangguan jaringan seperti ini, kegiatan pelayanan terpaksa dihentikan.

4. Jumlah loket yang tersedia pada umumnya hanya 1 (satu) loket yang tentunya tidak bisa mengatasi banyaknya jumlah wajib pajak sehingga menimbulkan banyaknya antrian. 
5. Terbatas pada jam operasiaonal tertentu. Pelayanan pembayaran pajak melalui Online pada umumnya memiliki jam operasional yang lebih singkat sampai jam 14.00 siang.

\section{SARAN}

Berdasarkan uraian tersebut diatas maka yang menjadi saran penelitia adalah sebagai berikut :

1. Loket yang disediakan Kantor Samsat Kabupaten Timor Tengah Selatan hanya 1 ( satu) loket, sehingga menimbulkan banyak antrean, oleh karena itu disarankan agar menambahkan loket pelayanan pendaftaran atau penyerahan untuk mengurangi panjangnya antrian dalam proses pembayaran pajak.

2. Kiranya Kantor Samsat Kabupaten Timor Tengah Selatan, untuk menyiapkan vendor cadangan untuk mengantisipasi jika vendor indur bermasalah atau rusak sehingga menghindari hilangnya data yang sudah direkam.

3. Agar jam operasional pelayanan pembayaran pajak melalui Online di perpanjang sampai jam 16.00 wita.

4. Agar Samsat Kabupaten mengadakan Sosialisasi secara bertahap kepada masyarakat wajib pajak melalui sistem Online mengenai pengurusan pembayaran Pajak Kendaraan Bermotor.

\section{DAFTAR PUSTAKA}

As, Moener 1995, Pelayanan yang Berkualitas. Gramedia Pustaka Utama : Jakarta

B. Anderson, 2002. Perenggangan untuk Orang Kantoran, penerjemah : Ratih Ramelan. PT Serambil Ilmu Semesta, Jakarta

B, Budiardjo, 1991. Komputer dan Masyarakat. PT. Elex Media Komputindo. Jakarta

Dedy Mulyana, 2000. "Ilmu komunikasi, Pengentar" Bandung : Remaja Rosadakarya

Danim, Sudarman 2004. Motivasi Kepemimpinan dan Efektivitas Kelompok. Penerbit Rineka Cipta. 
Effendy, Ujang Onong, 1989. Kamus komunikasi. Bandung, CV. Bandar Maju

f. siagian, (1987), Penelitian Operasioanal : Teori dan Praktek, Cetakan ke 1 Penerbit UI, Jakarta.

Huseini. Martani dan Hari Lubis. Teori Organisasi ( Suatu Pendekatan Makro ).

PAU. Ilmu-ilmu Sosisal UI

Indrajit, Richardus Eko (2005). E-Government in Action. Yogyakarta:Andi Offset.

Indrawijaya Adam L, 1989, Perubahan dan Pengembangan Organisasi, Sinar Baru Bandung, Bandung

Supriatman, 2002, Manajemen Pelayanan Umum di Indonesia, Jakarta: Bumi Aksara

Pamudji, 1994, Kualitas Pelayanan Publik, Cetakan ke 1 Penerbit UI, Jakarta.

Raharjo budi. 2001. Akuntansi dan Keuangan Untuk Manajer Non Keuangan.

CV. Andi Yogyakarta: Yogyakarta ..(2002). Membangun Aplikasi E-Government

Jakarta: PT Elek Media Komputindo

Moenir, H.A.S. 2002. Manajemen Pelayanan Umum di Indonesia, Jakarta: Bumi Aksara.

Parminto dan Atik Septi Winarsi tahun 2005, Manajemen Pelayanan, Universitas Gadjah Mada: Yogyakarta.

Kurniawan, J. Luthfi dan Puspitosari, Hesri. 2007. Wajah Buram Pelayanan Press. San Diego

Moenir,H.A.S. 2002, Wajah Pelayanan Publik Umum di Indonesia. Jakarta: Bumi Aksara.

Sarundajang, S.H. 2003. Birokrasi Dalam Otonomi Daerah, jakarta : Pustaka Sinar Jaya. 